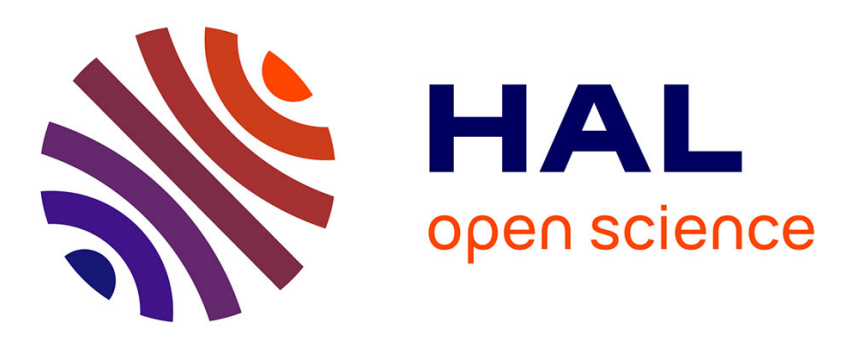

\title{
Resilience of a beef cow-calf farming system to variations in demographic parameters.
}

Anne France Viet, Pauline Ezanno, Etienne Petit, Jean Devun, Rémy

Vermesse, Christine Fourichon

\section{- To cite this version:}

Anne France Viet, Pauline Ezanno, Etienne Petit, Jean Devun, Rémy Vermesse, et al.. Resilience of a beef cow-calf farming system to variations in demographic parameters.. Journal of Animal Science, 2013, 91 (1), pp.413-424. 10.2527/jas.2011-5058 . hal-02645730

\section{HAL Id: hal-02645730 \\ https://hal.inrae.fr/hal-02645730}

Submitted on 29 May 2020

HAL is a multi-disciplinary open access archive for the deposit and dissemination of scientific research documents, whether they are published or not. The documents may come from teaching and research institutions in France or abroad, or from public or private research centers.
L'archive ouverte pluridisciplinaire HAL, est destinée au dépôt et à la diffusion de documents scientifiques de niveau recherche, publiés ou non, émanant des établissements d'enseignement et de recherche français ou étrangers, des laboratoires publics ou privés. 


\title{
Resilience of a beef cow-calf farming system to variations in demographic parameters ${ }^{1}$
}

\author{
A.-F. Viet, ${ }^{*}{ }^{2}$, P. Ezanno, $* \dagger$ E. Petit, $\$$ J. Devun, $\S$ R. Vermesse,\# and C. Fourichon* $*$ \\ *INRA, UMR1300 BioEpAR, BP 40706, F-44307 Nantes, France; †LUNAM Université, Oniris, UMR BioEpAR, F-44307 \\ Nantes, France; FRGDS Bourgogne, F-21000 Dijon, France; §Institut de l'Elevage, Service Fourrages et Conduites des \\ Troupeaux Allaitants, UMT PASF, F-63170 Aubière, France; and \#GDS 35, F-35042 Rennes, France
}

\begin{abstract}
Beef cow-calf farming systems are assumed to be resilient to biological disturbances that induce variations in herd demography; however, this hypothesis has not been fully investigated to date. Modeling is an interesting approach to study farming system resilience and to evaluate the impact of biological disturbances, taking into account interactions between system components, including biological variability and management practices. Our objective was to evaluate the resilience of beef cow-calf farming systems to variations in fertility and mortality using a modeling approach. We studied the direct effect of variations in demographic parameters on production objectives without explicitly representing the causes of the variations. We developed a stochastic model to represent the population dynamics of a beef cow-calf herd with breeding by natural service and biological processes occurring at the animal level. The
\end{abstract}

model was validated by comparing observed and simulated distributions of the calving-to-calving interval, which were found to be consistent. Resistance was evaluated by the proportion of simulations where the objective in terms of number of weaned calves is reached even when there is a disturbance that persists for $10 \mathrm{yr}$. Reversibility was evaluated by the time needed to return to the predisturbance production level. Beef cow-calf farming systems did not appear to be resistant to variations in mortality and infertility rates except when increases in the infertility rates were low ( 0.02 for cows and 0.03 for heifers). Critical situations, consequently, may emerge with regard to farm production if management practices are not adapted. Reversibility was observed for disturbances that persist for up to $5 \mathrm{yr}$. However, the system needed 2 to $3 \mathrm{yr}$ to recover its predisturbance production level and up to $4 \mathrm{yr}$ after an increase in cow infertility of 0.12 .

Key words: cow-calf herd, fertility, modeling, mortality, population dynamic, production

(C) 2013 American Society of Animal Science. All rights reserved.

\section{INTRODUCTION}

Beef cow-calf farming systems are said to be resilient (i.e., farmers are able to achieve a long-term production plan when disturbances impacting herd demography occur; Dedieu and Ingrand, 2010; Nozières et al., 2011). However, resilience has not been evaluated with regard to herd productivity. Farmers may anticipate disturbances by keeping more animals than needed, with this buffering strategy mitigating

\footnotetext{
${ }^{1}$ This work was carried out with the financial support of the French Research Agency, programs Programme Agriculture et Développement Durable, project ANR-05-PADD-014 (ACDUQ), and Investments for the future, project ANR-10-BINF-07 (MIHMES). The authors thank Vincent Robergeot (GDS 71) for his participation in the discussions to define assumptions on the herd demography.

${ }^{2}$ Corresponding author: anne-france.viet@oniris-nantes.fr

Received December 22, 2011.

Accepted September 6, 2012.
}

the worst impacts of disturbances (Gunderson, 2000). Unanticipated variations in animal fertility and mortality that may persist for a few months or longer can jeopardize farm production during the current year and future years. Two components of resilience are involved (Palumbi et al., 2008): resistance (i.e., the ability of a system to ensure current and future production irrespective of medium-term disturbances) and reversibility (i.e., its ability to return to a previous situation after a shorter disturbance).

A modeling approach complements observational studies by enabling an ex-ante evaluation of the resilience of a farming system to disturbances. Observational studies highlight possible options available to farmers to adapt their farming system to disturbances (Lemery et al., 2005; Dedieu and Ingrand, 2010) or to evaluate technical and economic results (Liénard et al., 2002; Mosnier et al., 2010). Modeling 
allows herd dynamics with different initial situations to be evaluated. Variations in production levels can be attributed to a given demographic variation. To evaluate the probability of a farm not reaching a production objective, a stochastic model is needed. Published stochastic models (Doren et al., 1985; Tess and Kolstad, 2000; Reisenbauer Leesburg et al., 2007; Pérochon et al., 2011) can only be used to evaluate system resilience to variations associated with forage availability and quality.

Our objective was to evaluate resistance and reversibility of beef cow-calf farming systems to short- and medium-term variations in fertility and calf mortality using a modeling approach.

\section{MATERIALS AND METHODS}

Animal Care and Use Committee approval was not obtained for this study because no animals were used.

\section{Modeling the Demography of a Beef Cow-Calf Herd}

The production objective of beef cow-calf farmers is the production of animals for sale under given resource constraints (such as land). Under these constraints, a proxy of the production objective can be defined by the number of calves weaned per year. Females are raised and bred to produce weaned calves, which are sold after a fattening period. Before weaning, calves are kept with their mothers for suckling. To ensure future production, some weaned female calves are not sold and instead are kept in the herd as heifers to renew the breeding stock. Farmers keep more animals than needed for breeding to compensate for anticipated infertility and mortality of calves before weaning. Unexpectedly high calf mortality or low fertility reduces the number of weaned calves, thereby decreasing productivity and the number of female calves that can be kept for reproduction in the future. Various disturbances can induce variations in fertility and calf mortality. For example, climate change has been reported to influence forage quality (Olesen and Bindi, 2002), which may have a medium- to long-term impact on fertility and growth rates and thus on farm productivity. Infections that last a few months, such as bovine respiratory diseases (Assié et al., 2004), also may affect a system over a short period of time. We assumed that farmers maintained a constant production objective when facing short- and medium-term disturbances. Farmers determine their production objective, defined here as the number of weaned calves, by identifying the maximum number of animals that they can keep for breeding given the resource constraints of their farms. This number influences, in turn, the future number of animals calving. To verify over time whether their objectives can be achieved, farmers then rely on intermediate indicators: the number of animals kept for breeding and the number of animals calving. These indicators may be considered to be intermediate targets. By evaluating these indicators, farmers can adjust the system, if needed, during the production cycle. At weaning, farmers keep a certain number of young females for breeding; the number is determined by the production objective that they fix for the future. Breeding is managed by farmers through their selection of a given number of 2-yr-old heifers and cows.

The farming system modeled and used for simulations in this paper was based on the characteristics of beef cow-calf herds in 1 of the main beef production regions in France. The model represented the demographic dynamics of a beef cow-calf herd with breeding by natural service. Both biological processes at the animal level and herd management by the farmer were represented. Biological processes included birth, mortality, aging, fertility, and fecundation. Herd management included breeding, purchase, sale, and culling decisions. To account for biological variability that exists even without disturbances and to describe various herd dynamics, the model was stochastic. The model was individual based and simulated with a discrete-event approach, programmed in Java (Flanagan, 2005).

Over time, animals in the herd were classified into states according to their age and physiological status (Fig. 1): Nc for calves from birth until weaning, Hf for fattening heifers after weaning until exit from the herd, Hk for heifers kept for breeding (less than $2 \mathrm{yr}$ old), $\mathbf{H b}$ for bred heifers, $\mathbf{C p}$ for cows from the first pregnancy diagnosis until the fattening decision, $\mathbf{C f}$ for cows from the fattening decision until culling, and $\mathbf{M}$ for fattening males after weaning until exit from the herd. For breeding, bulls ( $\mathbf{B u})$ were purchased and kept on the farm until culling. Because of the individual-based approach, all transitions between states were applied to each animal.

Newborn animals were in status Nc (Fig. 1). Twin birth occurred with probability $\delta$ (Table 1 ) assuming that calves were of the same gender. The gender of the calf was simulated stochastically according to a Bernoulli distribution with a probability of $50 \%$. Calf mortality before weaning occurred with probability $\mu$ (Table 1 ). The age at death ad (in days) was then simulated according to a distribution consistent with observed data (Fig. 2). Observed ages at death for unweaned calves in commercial herds in Bourgogne during the first 6-mo period of 2006 were extracted for parameter definition. We defined and compared different distributions using a mean-square error. A mixture distribution was selected by experts to better account for the high probability of death during the first $5 \mathrm{~d}$ after birth. First, the period between birth and death $\alpha$ was selected using a multinomial distribution (Eq. [1]). Then, the age at death was 


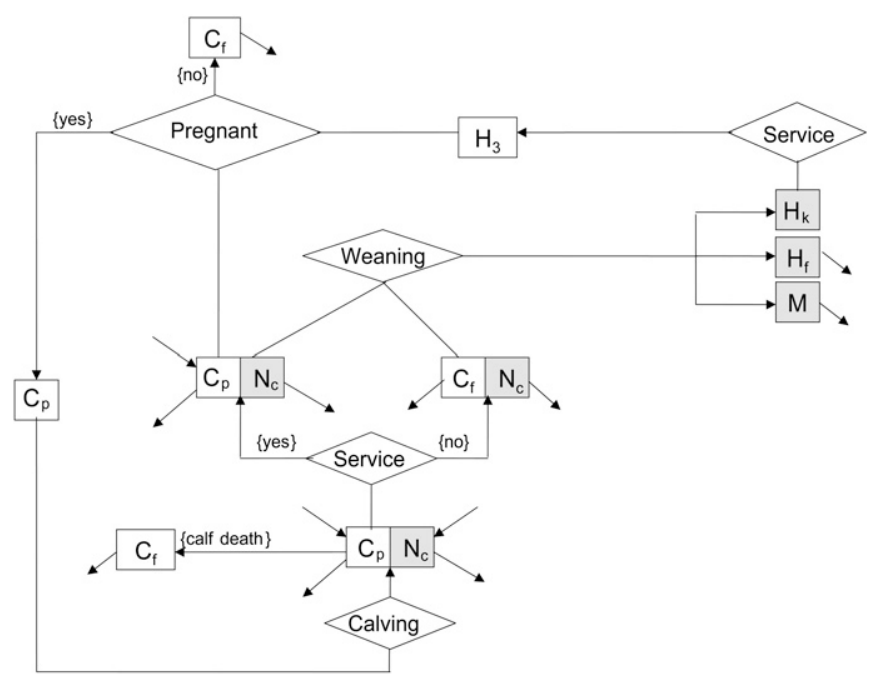

Figure 1. Diagram of the model: consecutive states for a young animal from birth to breeding age (in gray) and for an adult female animal over the course of the reproduction cycle (in white). A diamond represents an event or a branching point. Groups of animals for which the event or the branching point is applied are linked to the diamond by a line. At a specified time, an animal can be in only 1 of the states: $\mathrm{N}_{\mathrm{c}}=$ calf (newborn), $\mathrm{Cp}=$ cows, $\mathrm{Cf}=$ fattening cows, $\mathrm{H}_{\mathrm{b}}=$ bred heifers ( 2 to 3 yr old), $\mathrm{H}_{\mathrm{k}}=$ heifers, $\mathrm{Hf}=$ fattening heifers, $\mathrm{M}=$ males. Bulls are not raised in the herd and are not represented here.

simulated according to either a uniform (if $a d<5 \mathrm{~d}$ ) or an exponential distribution (if $a d \geq 5 \mathrm{~d}$; Eq. [1]):

$$
\alpha=\left\{\begin{array}{l}
0.265 a_{d} \sim U[0,1] \\
0.078 a_{d} \sim U[1,2] \\
0.056 a_{d} \sim U[2,3] \\
0.038 a_{d} \sim U[3,4] \\
0.026 a_{d} \sim U[4,5] \\
0.537 a_{d} \sim 5+\exp (0.01675)
\end{array}\right.
$$

To reach the target number of weaned calves, we assumed that it was possible to purchase a calf after a calf mortality event before the breeding period. This happened only if the observed number of calving ani- a)

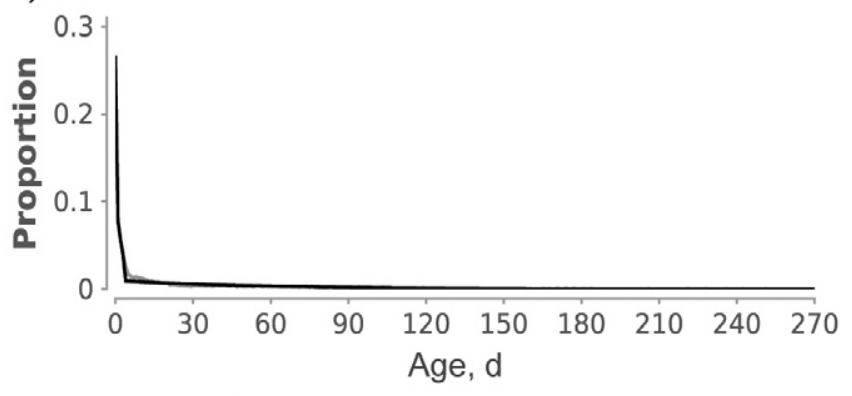

b)

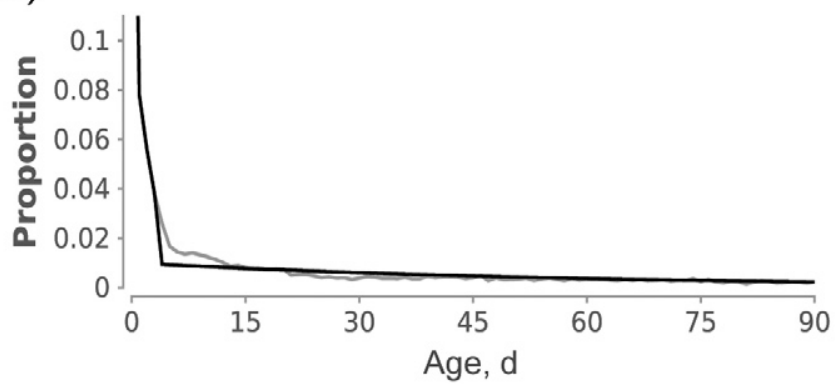

Figure 2. Distributions of calf age at death: observed data in gray (unpublished data from database) and simulations (based on Eq. [1]) in black. Representation of the distribution (a) until the age of $270 \mathrm{~d}$ and (b) between the ages of 0 and $90 \mathrm{~d}$.

mals was below the intermediate target in terms of calving animals, if the proportion of pregnancy was below a threshold $\psi$ (Table 1), and if the proportion of dead calves was greater than a threshold $\theta$ (Table 1). The purchase occurred only if a calf of nearly the same age could be purchased (probability $\lambda$; Table 1).

In case of an involuntary culling of a cow, the future of its calf depended on its age. Involuntary culling of a cow occurred with probability ${ }^{v_{C}}$ (Table 1$)$. The time of culling $\zeta$, in days after calving, was selected using a

Table 1. Value of parameters used for the simulation experiments at the animal level

\begin{tabular}{lll}
\hline \hline Parameters & & \multicolumn{1}{c}{ Description } \\
\hline$\delta$ & Probability of twin birth & \\
$\mu$ & Probability of calf mortality & \\
$\lambda$ & Probability of purchasing a calf for adoption & 0.035 \\
$v_{C}$ & Probability of involuntary culling for a cow & 0.9 \\
$v_{B u}$ & Probability of involuntary culling for a bull & 0.02 \\
$\kappa_{H}$ & Probability of infertility for heifers & 0.02 \\
$\kappa_{C}$ & Probability of infertility for cows & 0.02 \\
$\kappa_{B u}$ & Probability of infertility for bulls & 0.08 \\
$\rho$ & Reduction of the bull fertility associated with the simulated involuntary culling & 0.02 \\
$\theta$ & Threshold of the simulated proportion of dead calves to allow a purchase & 0.125 \\
$\psi$ & Threshold of the simulated pregnancy proportion to allow a purchase & 0.20 \\
$\pi$ & Threshold of the age of the calf at time of its mother involuntary culling for an adoption (in d) & 120 \\
$v$ & Threshold of the age of cows to be kept for breeding (in years) & 14 \\
$\varphi$ & No. of days after calving before breeding (in days) & 20 \\
$\sigma$ & Length of the reduced fertility period before involuntary culling for a bull (in days) & 30 \\
\hline
\end{tabular}


multinomial distribution based on expert knowledge and observed data:

$$
\zeta=\left\{\begin{array}{l}
0.18 a_{c} \sim U[0,7] \\
0.05 a_{c} \sim U[7,14] \\
0.04 a_{c} \sim U[14,21] \\
0.73 a_{c} \sim U[21,365] .
\end{array}\right.
$$

At the time of involuntary culling, the calf was weaned if older than a threshold age $\pi$ (Table 1). If younger, it was adopted either by another cow within the herd that had lost her calf a few days before or by a purchased cow. The age of any purchased cow $a p$ was simulated between 3 and 6 yr according to a triangular distribution [Triang $(a, b, c)$, with $a=1,095 \mathrm{~d}$ (minimum value), $b=2,190 \mathrm{~d}$ (maximum value), and $c=1,825 \mathrm{~d}$ (most likely value)]. The corresponding density function $f_{T}(\cdot)$ is given by

$$
\begin{array}{rlr}
f_{T}(x) & =\frac{2(x-1095)}{(2190-1095)(1825-1095)}, \quad 1095 \leq x \leq 1825, \\
& =\frac{2(2190-x)}{(2190-1095)(2190-1825)}, \quad 1825 \leq x \leq 2190 .
\end{array}
$$

Calves were weaned at a fixed date (October 15) irrespective of age. All males were kept for fattening before being sold (transitioned $\mathrm{Nc}$ to $\mathrm{M}$ ). A fixed number of heifers were kept (transitioned $\mathrm{Nc}$ to $\mathrm{Hk}$ ) and reared for 1 yr before breeding. The first breeding occurred at around $2 \mathrm{yr}$ old. All heifers that were not selected for breeding were fattened (transitioned Nc to Hf) and then sold.

Every year, the farmer decided which animals were or were not to be bred using the common practice of beef cattle herd farmers in France. All heifers older than 2 yr remaining in the herd were selected for breeding (transitioned $\mathrm{Hk}$ to $\mathrm{Hb}$ ). They all were raised in the same subgroup with a bull during the breeding period. The number of cows kept for breeding thus was the intermediate target number for breeding animals minus the number of bred heifers $(\mathrm{Hb})$. All primiparous cows with a living calf were kept for breeding. Cows older than a threshold $v$ (Table 1) and cows without living calves were not selected for breeding except when the intermediate indicators were not reached. Among other cows with a living calf, a random selection was made to use for breeding. We assumed here that the farmer did not consider the genetic value of cows for selection. Cows kept for breeding were separated into subgroups, with each subgroup containing a bull. The breeding period was the same each year. It began when the farmer introduced a bull into each subgroup of animals. The period began earlier for heifers than for cows (March 15 vs. April 1). To have all animals calving within a short time period, the bull stayed with the females during a limited period of time. The period ended when the bull was removed from each subgroup
(August 15).The length of the breeding season was typical of the beef herds modeled. At the time of pasture rotation in midsummer (July 15), the subgroups were mixed, and new subgroups were constituted. Among these new subgroups, 1 had a reduced breeding period (ending in midsummer). The oldest female calves with their dams were in this subgroup. Cows not kept for breeding moved from $\mathrm{Cp}$ to $\mathrm{Cf}$ at the beginning of the breeding period and were sold after their calves were weaned.

Whether or not a cow became pregnant depended on cow fertility, time spent with a bull, and bull fertility. After calving, an animal was assumed to be unavailable for breeding (before first estrus) for a few days ( $\varphi$, Table 1). Infertility of heifers and cows occurred with probabilities $\kappa H$ and $\kappa_{C}$, respectively (Table 1). To determine if the time spent with a bull was sufficient for conception, a delay before a successful mating was simulated as the sum of 2 variables: the time delay before the first estrus and the delay between the first estrus and the successful mating, simulated according to triangular distributions Triang $(0,30,21)$ and $\operatorname{Triang}(0,90,21)$, respectively. If the simulated time of successful mating fell after the exit of the bull, the cow was nonpregnant. Moreover, at the time of successful mating for a cow, the bull might be infertile with probability $\kappa B u$ (Table 1 ). In case of failure, this cow was then nonpregnant, and another successful mating time was simulated. All pregnant cows (staying in state $\mathrm{Cp}$ ) and heifers (transitioned $\mathrm{Hb}$ to $\mathrm{Cp}$ ) were raised together in winter and separated from nonpregnant animals. Calving occurred $285 \mathrm{~d}$ after a successful mating and at least 1calf was born. Nonpregnant animals were fattened (transitioned $\mathrm{Hb}$ to $\mathrm{Cf}$ and $\mathrm{Cp}$ to $\mathrm{Cf}$ ) before leaving the herd.

Breeding bulls were replaced by purchase. Each year, a randomly selected bull was culled and replaced by a purchased bull. After the involuntary culling of a bull during the breeding period, a replacement bull was purchased. Involuntary culling occurred with probability $v B u$ (Table 1). Time of replacement was then simulated according to a uniform distribution over the breeding period. We assumed here that the involuntary culling was related to a problem inducing a reduced fertility $\rho$ (Table 1) within a fixed period before replacement $\sigma$ (Table 1).

\section{Simulations}

Default Parameters. We chose parameter values (Table 1) consistent with typical beef cow-calf farming systems in one of the main beef production areas of France (Bourgogne). The target number of weaned calves was defined as 60 , and the intermediate target numbers were selected to be consistent with this objective ( 72 breeding animals and 65 calving animals). 
Initial Conditions. To have an initial herd with an age structure and initial characteristics of each animal consistent with the herd management modeled, the herd was derived from 1 simulation rather than being randomly generated. The simulation began at time of weaning (October 15), and the herd consisted of 168 animals. At the beginning of the simulation, $20 \%$ of the pregnant animals in the initial herd were heifers.

Model Outputs. Model outputs were related to the objective of the farmer and the related intermediate target numbers of animals to evaluate the resistance and reversibility of the system. The simulated number of calves weaned per year was computed and compared with the objective. We also calculated the simulated number of animals kept for breeding and the simulated number of animals calving to compare them with the corresponding intermediate target numbers. First, model outputs were described over several years to identify if the proportion of simulations reaching the target numbers was nearly constant over time. Yearly outputs were then pooled to compare scenarios without taking into account the effect of time. To identify which herd demography characteristics hindered the achievement of objectives, we calculated the simulated proportion of dead calves at the herd level, the simulated global proportion of pregnancy, and the simulated number of involuntary culled animals. We compared the simulated distributions of these 3 outputs when the objective was not reached to those computed with all of the repetitions. To compute the distributions, we pooled all of the results irrespective of the simulation and year. The distributions were compared using the Cramer-von Mises test (Sprent, 1989). To ensure a thorough description of the distribution of the simulated number of weaned calves, 200 repetitions were run. A simulation time of $10 \mathrm{yr}$ was chosen because it was considered sufficient to detect, when studying reversibility, a return to the situation before a disturbance when this disturbance lasts at most $5 \mathrm{yr}$.

Model Evaluation. No observed data on the objective in terms of number of weaned calves were available. We therefore chose to compare model results with herd demography characteristics that could be measured easily in the field. We compared the simulated proportion of pregnancy, the simulated repartition of calving dates, and the simulated proportion of dead calves with expert knowledge. To evaluate the consistency of the model variability, we compared observed and simulated distributions of the calving-to-calving interval for cows with at least 2 previous calving experiences. Observed calving-to-calving intervals for multiparous cows in 2006 were extracted for the simulated calving period only in beef cow-calf herds of a similar size to exclude data from large herds with other calving practices. The simulated distribution was calculated including all calving-to-calving intervals for multiparous cows irrespective of the simulation and year. The observed and simulated distributions of the calving-to-calving interval were compared using the Cramer-von Mises test (Sprent, 1989).

Evaluation of Resistance and Reversibility. To study the resistance and reversibility of a beef cow-calf farming system, disturbances inducing an increase in calf mortality, cow infertility, or heifer infertility were considered. The values of the 3 corresponding model parameters were modified accordingly (Table 2). To study resistance, parameter values were modified one by one over the entire simulation period (10 yr), representing a disturbance lasting a long period of time. We did not allow for adaptation of herd management by the farmer. The effects of disturbances on the achievement of both the final objective and the intermediate target numbers were evaluated and compared using the Cramer-von Mises test. To study reversibility, the values were modified one by one during yr 2, 3, 4, and 5 successively, and simulations were run over $10 \mathrm{yr}$. In this case, the reference situation was assumed to be the distribution of the number of weaned calves before the disturbance. To limit the effect of the initial herd structure, we randomly generated this distribution. Thus, 200 initial herds were generated by the model over an earlier $10 \mathrm{yr}$ period in which there was no disturbance (warm-up period). The distribution of the yearly number of weaned calves after the end of the disturbance was compared with the distribution before the disturbance. For reversibility, the system was assumed to return to the reference situation when there was no significant difference at a risk of 5\% by the Cramer-von Mises test.

\section{RESULTS}

\section{Model Evaluation}

The baseline simulated herd dynamics were consistent with expert knowledge. The interquartile interval of the simulated pregnancy proportion ( 0.90 to 0.94 ) was consistent with the expected pregnancy proportion (0.92 to 0.94 ). The median simulated date of calving was March 7, which falls within the interval reported

Table 2. Parameters values for the disturbances modeled (default values are given in bold)

\begin{tabular}{llc}
\hline \hline Parameter & \multicolumn{1}{c}{ Values for sensitivity analysis } & $\begin{array}{c}\text { Lengths of the } \\
\text { disturbance }\end{array}$ \\
\hline$\mu$ & $0.09,0.125 ; 0.15 ; 0.175 ; 0.2 ; 0.225 ; 0.25$ & $10 \mathrm{yr}$ \\
$\kappa_{C}$ & $0.08,0.1 ; 0.125 ; 0.15 ; 0.175 ; 0.2$ & $10 \mathrm{yr}$ \\
$\kappa_{H}$ & $0.02,0.05 ; 0.075 ; 0.1 ; 0.125 ; 0.15 ; 0.175 ; 0.2$ & $10 \mathrm{yr}$ \\
$\mu$ & $0.09,0.15 ; 0.2 ; 0.25$ & $2,3,4$, and $5 \mathrm{yr}$ \\
$\kappa_{C}$ & $0.08,0.1 ; 0.15 ; 0.2$ & $2,3,4$, and $5 \mathrm{yr}$ \\
$\kappa_{H}$ & $0.02,0.05 ; 0.1 ; 0.15 ; 0.2$ & $2,3,4$, and $5 \mathrm{yr}$ \\
\hline
\end{tabular}


by experts (between mid-February and mid-March). The median simulated proportion of dead calves at the herd level was 0.086 , which was consistent with the expectation (between 0.07 and 0.09).

The simulated and observed distributions of calvingto-calving intervals showed good agreement (Fig. 3), but the distributions were significantly different $(P<$ 0.01). The simulated calving-to-calving interval was slightly shorter than those observed. However, medians were close (364 and 368 in simulated and observed data, respectively). Whereas the 75 th percentiles were similar for the simulated and observed intervals (382 and 388, respectively), the 90th and the 95th percentiles for simulated intervals (398 and 408 respectively) were less than for observed ones (413 and 432, respectively).

The target number of weaned calves was reached in $77 \%$ of situations irrespective of the repetition or year. The intermediate target numbers of breeding and calving animals were reached in $87 \%$ and $73 \%$ of situations, respectively. The number of weaned calves was widely distributed each year, and its distribution over time reached equilibrium (Fig. 4). The median was barely greater than the target number (60).

The simulated distributions of pregnancy, calf mortality, and number of involuntary culled animals for all situations and for ones below the target number of weaned calves were significantly different $(P<0.05$; Fig. 5). Compared with the median for all situations, the median of the pregnancy proportions for pairs below the target number decreased (from 0.92 to 0.89 ), and the median proportion of dead calves increased (from 0.09 to 0.12 ). The median number of involuntary culled animals did not change.

\section{Evaluation of Resistance of Beef Cattle Farming Systems}

The proportion of repetitions in which the target numbers were not reached converged to a stable distribution except for a few values of the probability of calf mortality $\mu$ and the probability of heifer infertility $\kappa_{H}$. For example, the proportion of repetitions below the target number of

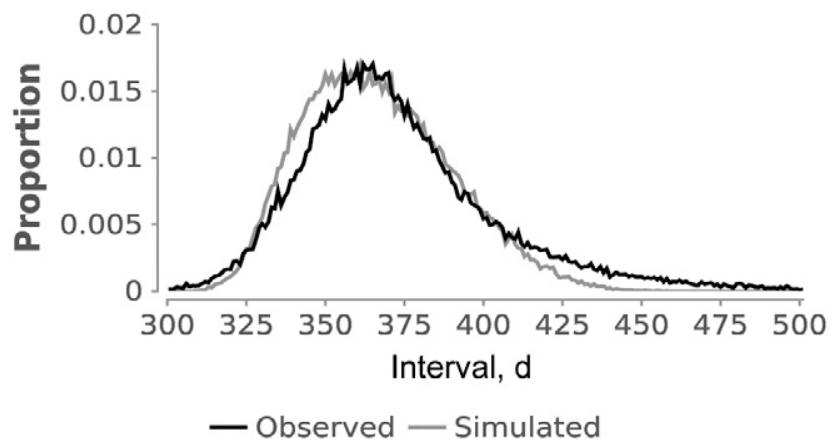

Figure 3. Distribution of calving-to-calving interval for cows: observed data (in 2006) in black and simulations in gray (200 repetitions, 10 simulated year). weaned calves showed stability at the end of $4 \mathrm{yr}$ for all values of $\mu$ considered (Fig. 6a). In contrast, no stability was observed at the end of $10 \mathrm{yr}$ for all target numbers when $\kappa_{H}=0.2$, for the number of breeding animals when $\kappa_{H}=0.15$, and for the number of breeding animals when $\mu$ $\geq 0.175$ (as shown in Fig. 6b). In this section, results from the first $4 \mathrm{yr}$ were disregarded, and those of the fifth year onward were pooled. In scenarios without stability, the effects illustrated by these representations therefore were underestimated slightly.

The probability of calf mortality $\mu$ directly decreased the number of weaned calves and indirectly decreased the number of breeding and calving animals (Fig. 7). The target number of breeding animals was reached in less than $75 \%$ of repetitions when $\mu>0.2$ compared with $96 \%$ of repetitions without disturbance (Fig. 7a). For $\mu$ $=0.25$, this intermediate target number was reached in only $56 \%$ of the repetitions. The target number of calving animals was achieved in at least $50 \%$ of repetitions compared with $68 \%$ of repetitions without disturbance (Fig. 7b). In less than $50 \%$ of the repetitions, the target number of weaned calves was reached when $\mu \geq 0.15$ (Fig. 7c). The proportion of repetitions with less than 46 weaned calves was less than $1 \%$ when $\mu \leq 0.175$ and increased to $16 \%$ when $\mu=0.25$ (Fig. 7c). Because of the increased calf mortality, more cows were culled, reducing the number of cows kept for breeding the next year. For example, when $\mu=0.25$, in $50 \%$ of the repetitions more than 6 cows were culled after the death of their calf over the 10 simulated years compared with 2 cows without disturbance. Although the culling of cows increased because of calf mortality, the proportion of repetitions with purchasing of cows and the average number of purchased animals were not modified. The proportion of repetitions with purchasing of calves barely increased with the probability of calf mortality $(0.41 \%$ when $\mu$ $=0.25$ compared with $0.08 \%$ for the situation without disturbance, on a yearly basis). The average number of purchased calves was not impacted.

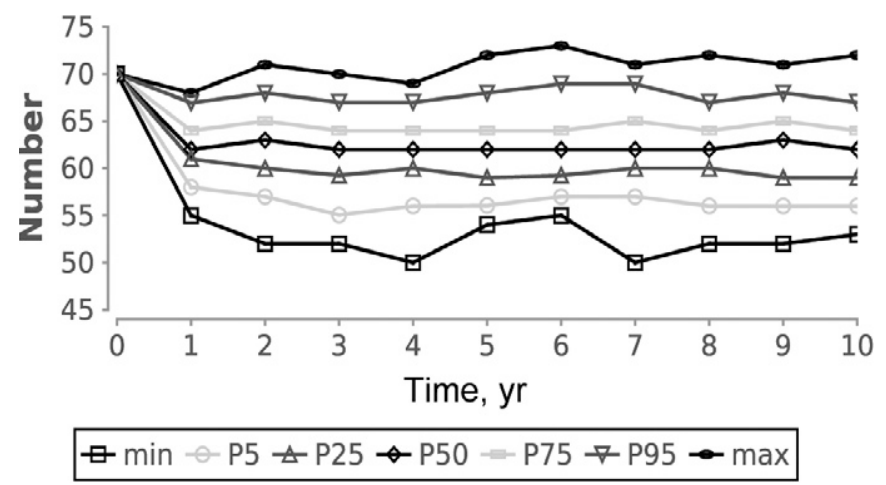

Figure 4. Distribution of the number of weaned calves over time. Description by the minimum, 5th, 25th, 50th, 75th, and 95th percentiles, and maximum (denoted min, P5, P25, P50, P75, P95, and max, respectively). 
The increase in the probability of cow infertility $\kappa_{C}$ decreased the numbers of breeding animals, calving animals, and weaned calves (Fig. 8). The target number of breeding animals was reached in less than $50 \%$ of the repetitions when $\kappa_{C} \geq 0.15$ compared with $96 \%$ without disturbance (Fig. 8a). A decrease in the number of calv-
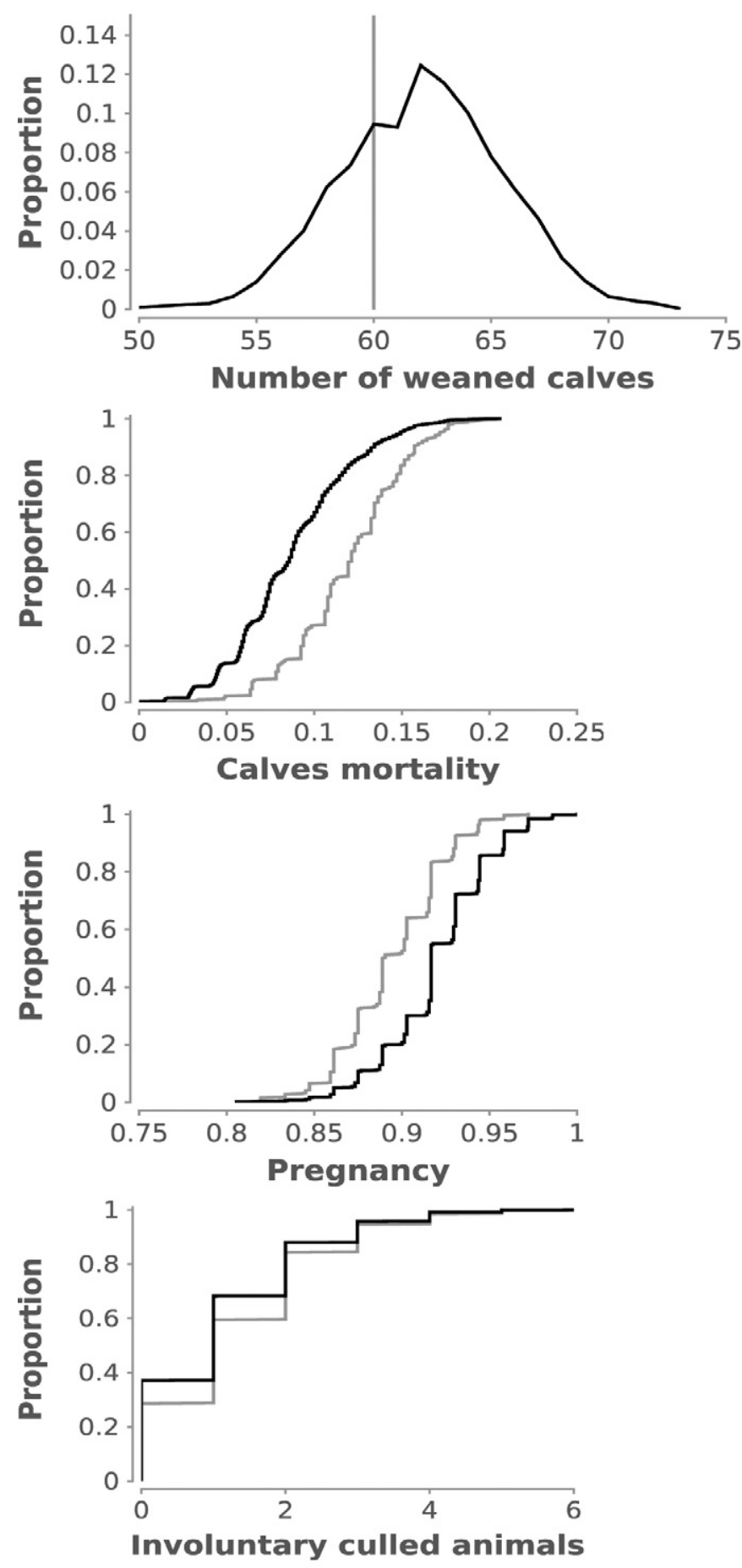

\section{Bellow objective - All}

Figure 5. Distribution of the number of weaned calves for all simulated situations irrespective of the repetition and the year. The target number is indicated by a vertical line. The simulated distributions at the herd level of the proportion of dead calves (calf mortality), the proportion of pregnancy, and the number of involuntary cullings for situations with fewer weaned calves than the objective are in gray, and the ones for all situations are in black. ing animals was observed even for the lowest increase in $\kappa_{C}$ (Fig. 8b). The target number of calving animals was reached in less than $25 \%$ of repetitions when $\kappa_{C} \geq$ 0.125 and was below $1 \%$ when $\kappa_{C}=0.2$. Because of the decrease in the calving number, the number of weaned calves decreased (Fig. 8c). The target number of weaned calves was achieved in less than $50 \%$ of repetitions when $\kappa_{C} \geq 0.125$ compared with $74 \%$ without disturbance and was below $4 \%$ when $\kappa_{C}=0.2$. The proportion of repetitions with less than 46 weaned calves was greater than $1 \%$ when $\kappa_{C} \leq 0.175$ and increased to $18 \%$ when $\kappa_{C}=0.2$ (Fig. 8c). As a greater number of cows were infertile, the number of cows culled because they were nonpregnant increased, and the number of cows culled because they were not kept for breeding (no service) decreased. As the number of cows among breeding animals decreased, the proportion of bred heifers increased with $\kappa_{C}$. This proportion stayed below $30 \%$ irrespective of the disturbance. As purchasing of cows was allowed only to replace a dead cow with a living calf that had not yet been weaned, purchasing of cows decreased when the probability of cow infertility increased $\left(37 \%\right.$ when $\kappa_{C}=0.20$ compared with $48 \%$ for the situation without disturbance, on a yearly basis). The proportion of repetitions with purchasing of calves increased with the probability of cow infertility but was always low ( $4 \%$ when $\kappa_{C}=0.20$ compared with $0.08 \%$ without disturbance).

The increase in the probability of heifer infertility $\kappa_{H}$ decreased the number of calving animals and, to
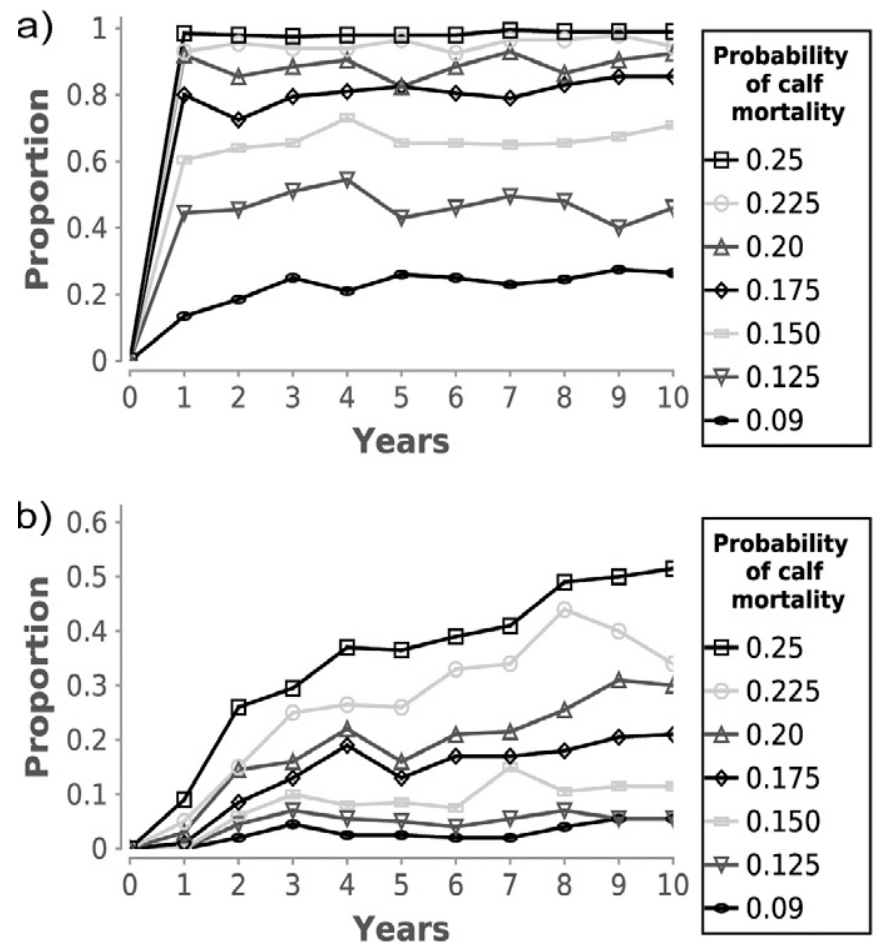

Figure 6. Proportion over time of repetitions below the target numbers of (a) weaned calves and (b) breed animals for different values of the probability of calf mortality $\mu$. The default value is 0.09 . 
a lesser extent, the number of weaned calves (Fig. 9). However, the associated decrease was smaller than the decrease induced by the other disturbances studied. The target number of breeding animals was always reached in more than $73 \%$ of the repetitions (Fig. 9a). The target number of calving animals was achieved in less than $50 \%$ of repetitions when $\kappa_{H} \geq 0.125$ and remained above $29 \%$ (Fig. 9b). Because of a small decrease in the number of calving animals, there was only a small decrease in the number of weaned calves (Fig. 9c). The target number of weaned calves was achieved in less than $50 \%$ of repetitions only when $\kappa_{H}=0.2$. The proportion of repetitions with less than 46 weaned calves always was
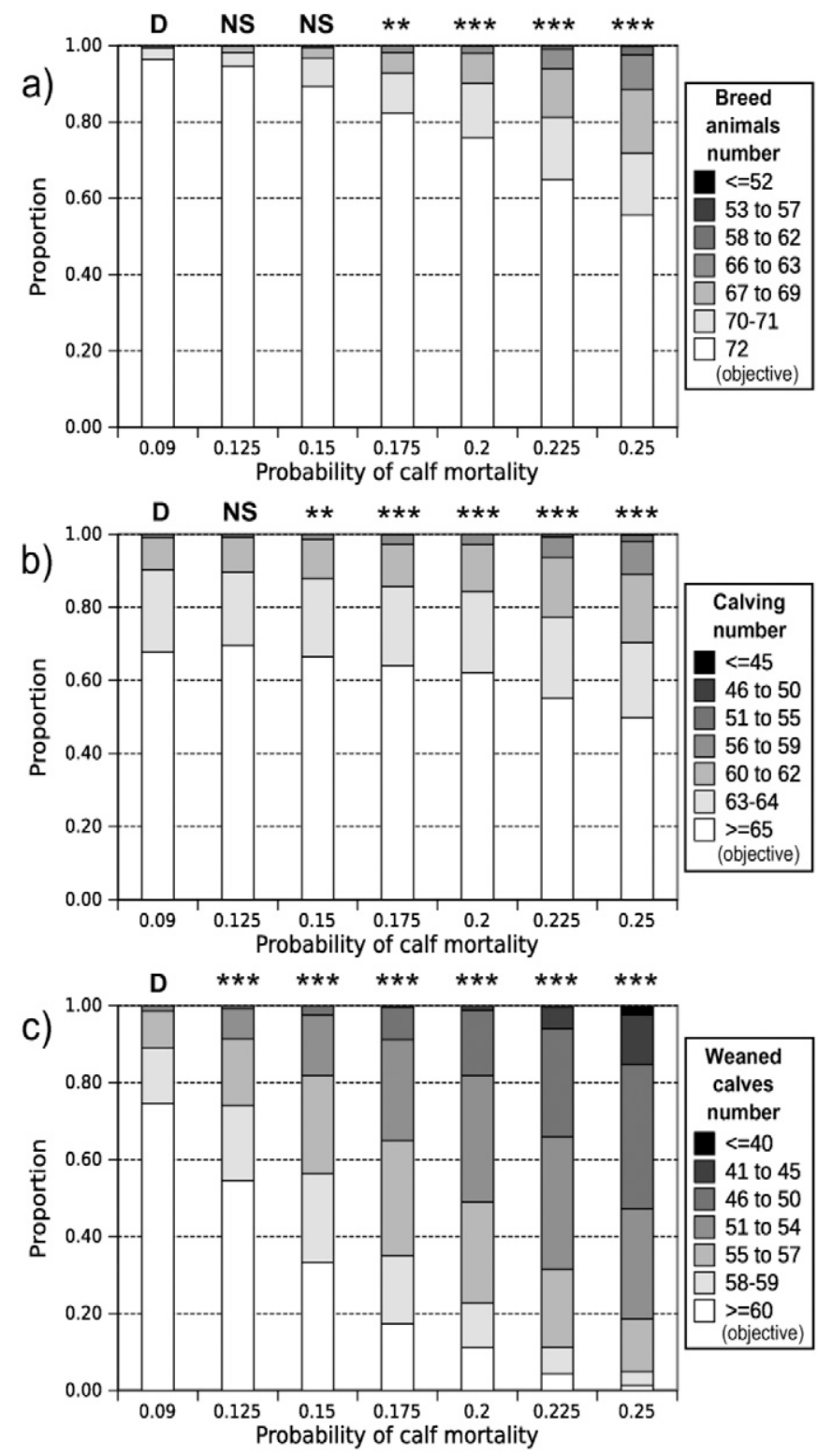

Figure 7. Effect of a disturbance inducing an increase of the calf mortality probability $\mu$ during $10 \mathrm{yr}$ on the distribution of the number of (a) breeding animals, (b) calving animals, and (c) weaned calves among all repetitions irrespective of the year between the 5th and the 10th year after the beginning of the disturbance. The default value of $\mu$ is 0.09 . The Cramer-von Mises test ( $P$-values: $* * *<1 \%, * *<5 \%, *<10 \%$, and NS otherwise) was used to compare the distributions for each probability to that of the default value (D). lower than $0.1 \%$ (Fig. 9c). The proportion of primiparous cows decreased when $\kappa_{H}$ increased. For example, the median proportion of primiparous cows was $16.6 \%$ when $\kappa_{H}=0.20$ compared with $19.4 \%$ without disturbance. For $\kappa_{H}=0.20$, the median number of animals culled because of no pregnancy over the 10 simulated years was 8 compared with 6 without disturbance. As purchasing of cows was allowed only to replace a dead cow with a living calf that had not yet been weaned, purchasing of cows did not change with the probability of heifer infertility. The proportion of repetitions with purchasing of calves increased with the probability of
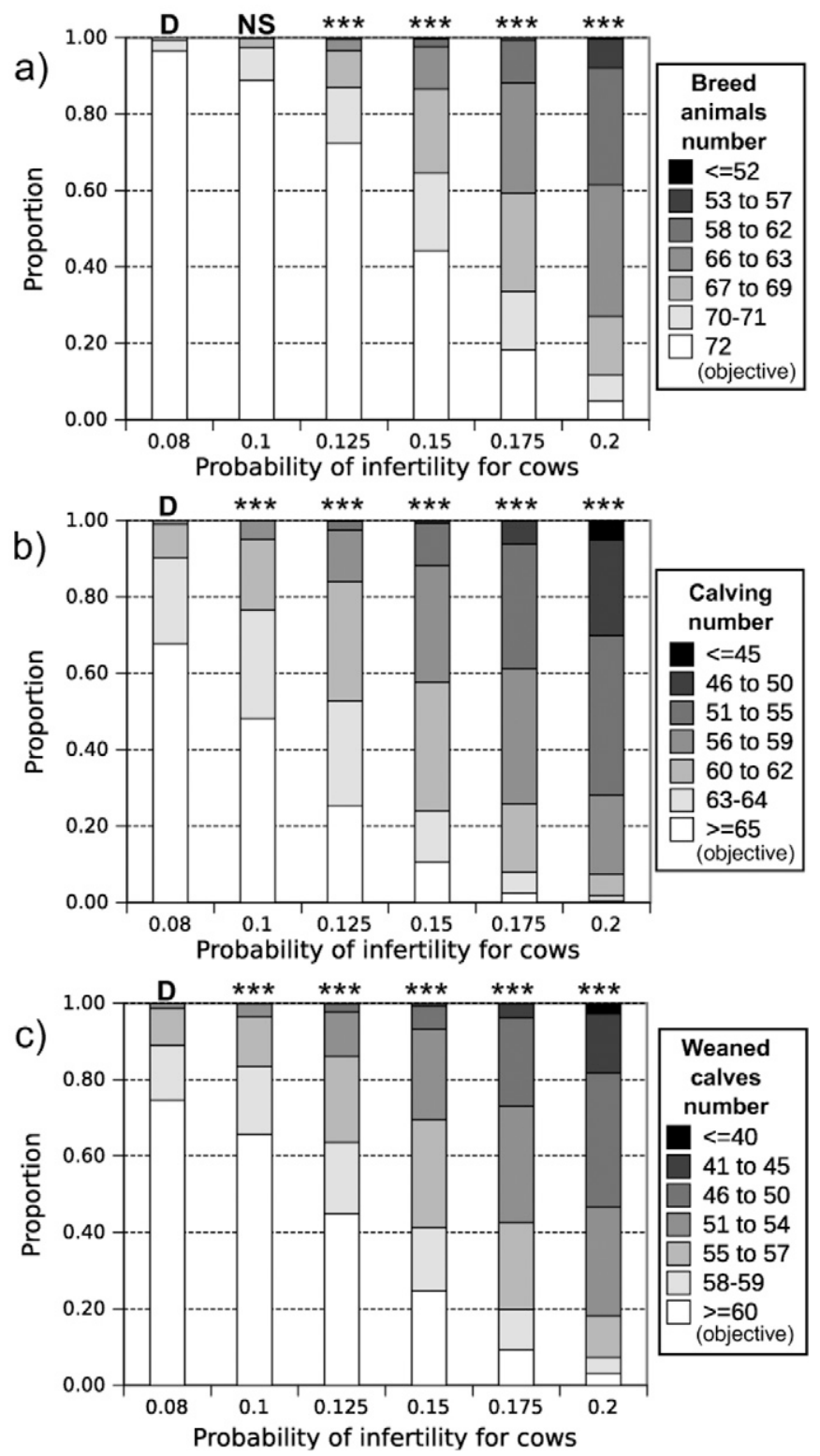

Figure 8. Effect of a disturbance inducing an increase of the infertility probability for cows $\kappa C$ during $10 \mathrm{yr}$ on the distribution of the number of (a) breeding animals, (b) calving animals, and (c) weaned calves among all repetitions irrespective of the year between the 5th and the 10th year after the beginning of the disturbance. The default value of $\kappa C$ is 0.08 . The Cramervon Mises test ( $P$-values: $* * *<1 \%, * *<5 \%, *<10 \%$, and NS otherwise) was used to compare the distributions for each probability to that of the default value (D). 
heifers infertility $\left(1.16 \%\right.$ when $\kappa_{H}=0.20$ compared with $0.08 \%$ without disturbance, on a yearly basis).

\section{Evaluation of Reversibility of Beef Cattle Farming Systems}

After an increase in calf mortality $\mu$ lasting 2 yr or longer, the distribution of the number of weaned calves returned to the previous equilibrium the year after the end of the disturbance $(P>0.05)$, except for $\mu=0.25$ (Fig. 10), for which up to $3 \mathrm{yr}$ was needed $(P<0.05$ during 1 to $3 \mathrm{yr}$ after the disturbance and $P>0.05$ after). For a 2-yr disturbance of the probability of cow infertility $\kappa_{C}$,
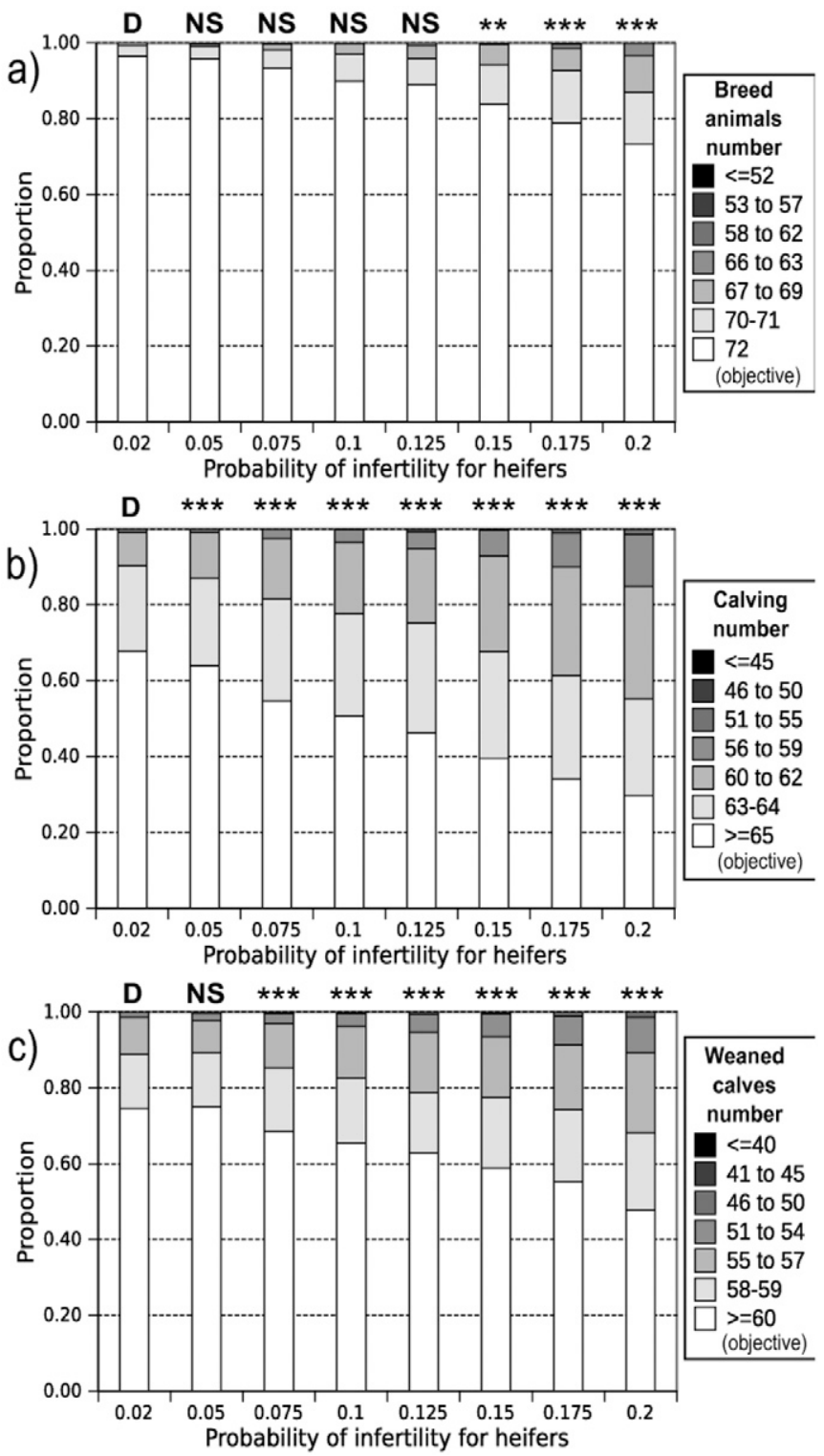

Figure 9. Effect of a disturbance inducing an increase of the infertility probability for heifers $\kappa_{H}$ during $10 \mathrm{yr}$ on the distribution of the number of (a) breeding animals, (b) calving animals, and (c) weaned calves among all repetitions irrespective of the year between the 5 th and the 10th year after the beginning of the disturbance. The default value of $\kappa H$ is 0.02 . The Cramervon Mises test ( $P$-values: $* * *<1 \%, * *<5 \%, *<10 \%$, and NS otherwise) was used to compare the distributions for each probability to that of the default value (D). the time to return to the previous situation was $2 \mathrm{yr}(P<$ 0.01 during $1 \mathrm{yr}$ after the disturbance and $P>0.05$ after), except when $\kappa_{C}=0.2$, for which $4 \mathrm{yr}$ were needed (Fig. $11 ; P<0.01$ during 3 yr after the disturbance and $P>0.05$ after). For longer disturbances, this time increased when the probability of cow infertility $\kappa_{C}$ increased: from $2 \mathrm{yr}$ when $\kappa_{C}=0.1$ to $4 \mathrm{yr}$ when $\kappa_{C}=0.2(P<0.05$ during 1 to $3 \mathrm{yr}$ after the disturbance and $P>0.05$ after). When the probability of heifer infertility was nearly doubled $\left(\kappa_{H}=0.05\right)$, the distributions of the number of weaned calves over time was not significantly different from the distribution before disturbance, even during the disturbance period and irrespective of its length $(P>0.10)$. For the other values of the probability of heifer infertility, the time needed after a short disturbance ( 2 or $3 \mathrm{yr}$ ) to return to the equilibrium increased when the probability increased: from $2 \mathrm{yr}$ when $\kappa_{H}=0.1(P<0.05$ during $1 \mathrm{yr}$ after the disturbance and $P>0.05$ after) to $3 \mathrm{yr}$ when $\kappa_{H}$ $=0.2$ (for a 2-yr disturbance; Fig. 12). For a 5-yr disturbance, the return was delayed, from $2 \mathrm{yr}$ when $\kappa_{H}=0.1$ to $3 \mathrm{yr}$ when $\kappa_{H}$ was 0.15 or greater $(P<0.05$ during 1 or $2 \mathrm{yr}$ after the disturbance and $P>0.05$ after).

\section{DISCUSSION}

In our model, the beef cow-calf farming system showed good reversibility to variations of demographic parameters but a lack of resistance to high variations that can jeopardize the economic viability of the farm. High increases in calf mortality or in cow infertility decreased the number of weaned calves from the first year and the number of heifers for reproduction a few years after the first year with the variation. This impact was amplified with each additional year of disturbance. As the production objective considered in this study directly impacts the net revenue of the farmer, the variation would impact the viability of the farming system. Other studies have focused on the impact of management practice on the economic results of the beef cow-calf farming system (Doren et al., 1985; Bourdon and Brinks, 1987; Pang et al., 1999; Tess and Kolstad, 2000; Roughsedge et al., 2003; Reisenbauer Leesburg et al., 2007). Here we focused only on a technical indicator. Studying the resilience of the system in terms of economic viability would require taking other farm activities into consideration, such as crops and other animal production (Darnhofer et al., 2010). A variation in demography over a few years can be absorbed by the economic results of other activities or can induce a change in farm activities to compensate for the disturbance (Ingrand et al., 2007; Astigarraga and Ingrand, 2010).

The range of variations of demographic parameters evaluated in this study was sufficiently large to cover observational variations irrespective of the cause. 


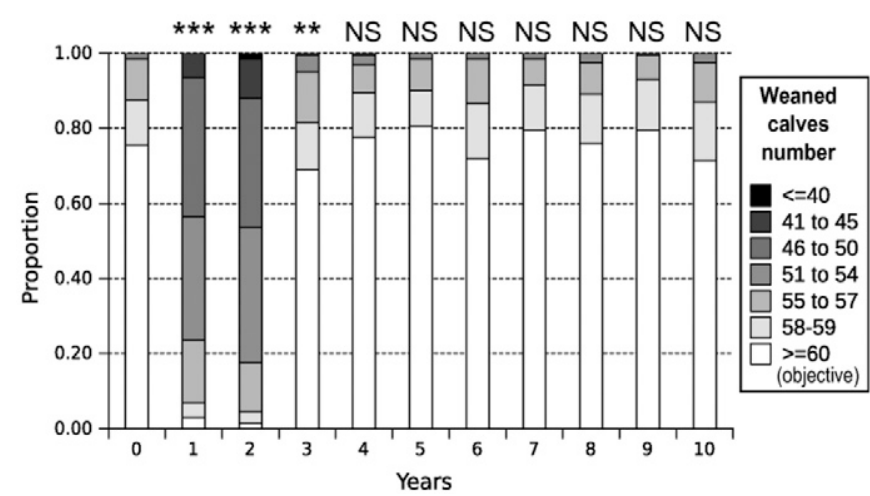

Figure 10. Distribution of repetitions according to the number of weaned calves over the years and $P$-values of the Cramer-von Mises test $(* * *<1 \%$, ** $<5 \%, *<10 \%$, and NS otherwise) when the calf mortality probability $\mu$ was modified at yr 1 during 2 yr (0.25 instead of 0.09). The Cramer-von Mises test was used to compare the distribution of the number of weaned calves each year to the reference (yr 0 at the beginning of the disturbance simulation).

However, for extreme values of these parameters, it is likely that farmers would change practices and not maintain their production objective. In the case of high mortality $(>20 \%)$ or infertility $(>20 \%)$, production was jeopardized greatly. If a disturbance lasted more than $2 \mathrm{yr}$, the time needed to return to the production level achieved before the disturbance was long. Farmers may change their management to prevent such low production over a long period. Farmers tend to adapt their herd management over time to respond to severe disturbances or in anticipation of a long-lasting one (Mosnier et al., 2009, 2010). Adaptation may consist of increasing purchases of animals and reducing culling. It would be of interest to study how such adaptive processes influence the resilience of a farming system. More knowledge is needed on how farmers choose to adapt because the adaptation process depends on the point of view of the farmers (Lemery et al., 2005).

As our objective was to better understand the functioning of a beef farming system subjected to a distur-

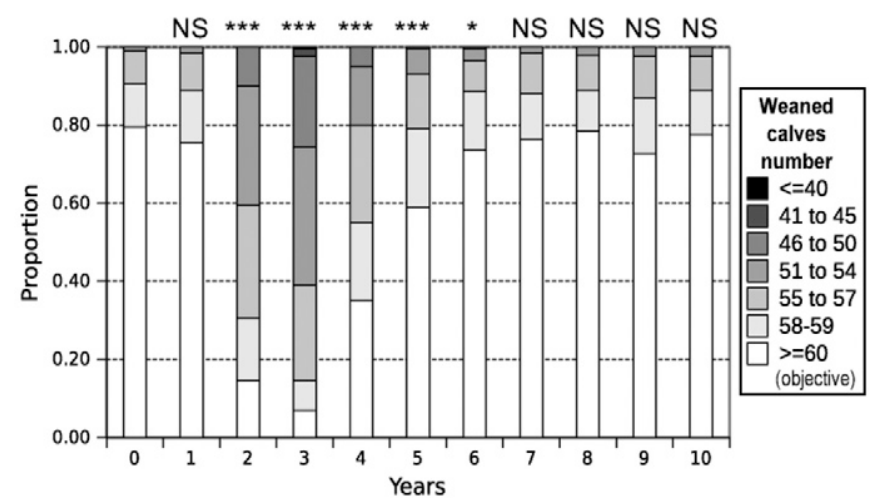

Figure 11. Distribution of repetitions according to the number of weaned calves over the years and $P$-values of the Cramer-von Mises test $(* * *<1 \%$, ** $<5 \%, *<10 \%$, and NS otherwise) when the infertility probability for cows $\kappa_{C}$ was modified at yr 1 during 2 yr (0.2 instead of 0.08$)$. The Cramer-von Mises test was used to compare the distribution of the number of weaned calves each year to the reference (yr 0 at the beginning of the disturbance simulation).

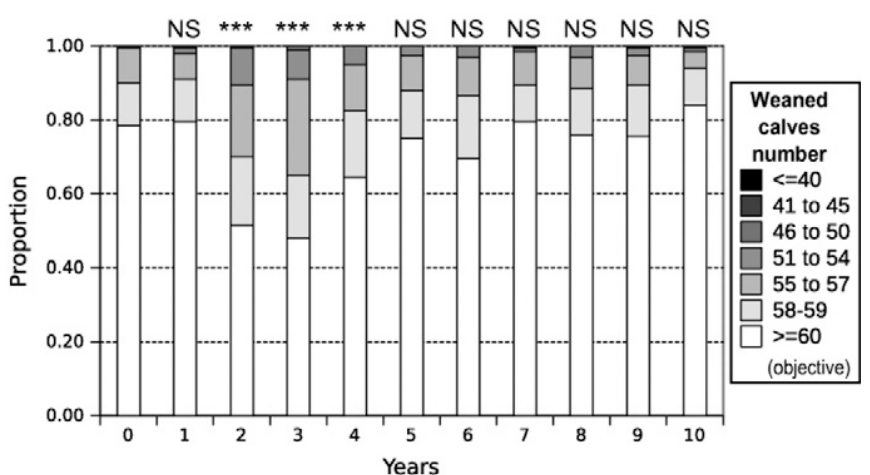

Figure 12. Distribution of repetitions according to the number of weaned calves over the years and $P$-values of the Cramer-von Mises test $(* * *<1 \%, * *$ $<5 \%, *<10 \%$, and NS otherwise) when the infertility probability for heifers $\kappa_{\mathrm{H}}$ was modified at yr 1 during 2 yr (0.2 instead of 0.02). The Cramer-von Mises test was used to compare the distribution of the number of weaned calves each year to the reference ( $\mathrm{yr} 0$ at the beginning of the disturbance simulation).

bance, we did not consider uncertainty relative to parameter values, which were assumed to be certain and constant over time. When a real herd is involved, the variability of model parameters and uncertainty should be considered. Mortality and infertility rates can vary over time according to various factors. Moreover, parameter values can be estimated with some errors from observed data. A sensitivity analysis could help in identifying the parameters that strongly influenced model outputs (i.e., those that should be estimated more precisely; Saltelli et al., 2000). However, because of the number of parameters to be considered and because our model was stochastic, such an analysis was not carried out.

As herds in Europe can be quite small, stochastic events can have large effects. The use of a stochastic model therefore was important. Model parameters were defined at the animal level. Because of the small size of the structured herd, the simulated demography at the herd level varied over time even without a disturbance. Such demographic variations at the herd level were consistent with variations in observed rates over time for a French farming system. In a context of larger herds, as can be found, for example, in the United States, stochastic variables are expected to have less severe effects on herd demography. However, the same model could be applied in such a context if the herd size and associated model parameters were changed, thereby enabling comparisons with other farming systems.

The stochastic models that have been published to date mechanically represent biological processes driving growth (Doren et al., 1985; Tess and Kolstad, 2000; Reisenbauer Leesburg et al., 2007; Pérochon et al., 2011), fertility (Doren et al., 1985; Tess and Kolstad, 2000; Reisenbauer Leesburg et al., 2007; Pérochon et al., 2011), and mortality (Doren et al., 1985; Tess and Kolstad, 2000; Reisenbauer Leesburg et al., 2007). Models have been used to evaluate the impact of forage quality on production (Doren et al., 1985; Tess and Kolstad, 2000) 
as well as the impact of management practices on technical performance (Pérochon et al., 2011) and economic viability (Doren et al., 1985; Reisenbauer Leesburg et al., 2007). These models could be used to evaluate system resilience to variations in forage availability and quality. However, variations in fertility and mortality can result from other causes, such as stress. Such variations cannot be simulated with these models. Our model, therefore, is simpler than previously published ones, but it enables the demography dynamics of a beef cattle herd to be simulated. Other characteristics can be introduced into the model if needed or the model can be coupled with another, for example, an epidemiological model (of a disease that induces disturbances in the demography).

Our individual-based model could be developed further to investigate the resilience of the system to various origins of variation in demographic parameters. To do so, a few extra parameters could be introduced into our model or a specific module to simulate biological processes could be added. For example, an easy adaptation would be to add the probability of difficult calving, resulting in increased mortality of calves (Nix et al., 1998). To study the impact of infectious disease on farming system resilience, our model could be coupled with a transmission model of a pathogen. To investigate the effects of resource availability, a growth model could be added (Jouven et al., 2008) with an explicit link between body condition and reproduction, as in Pérochon et al (2011). Finally, it may be necessary to represent more precisely the process determining fertility, such as estrus occurrence and probability of conception at each estrus, as in Blanc and Agabriel (2008).

Our model allowed us to simulate the resistance and the reversibility of a beef cow-calf farming system after a short- or medium-term variation in 1 demographic parameter at a time when all parameters were exactly known. With regard to the range of variations under study, the system was less resistant to variations in calf mortality and cow infertility than to variations in heifer infertility. In contrast, our study showed a greater reversibility of the system to variations in calf mortality than to variations in cow infertility. The magnitude of the drop in production shown here may result in changes in the management of the system itself or in the production objective associated with the capacity of the system to recover, which is another component of resilience.

\section{LITERATURE CITED}

Assié, S., H. Seegers, and N. Bareille. 2004. Incidence of respiratory disorders during housing in non-weaned Charolais calves in cow-calf farms of Pays de la Loire (western France). Prev. Vet. Med. 63:271-282.

Astigarraga, L., and S. Ingrand. 2010. Production flexibility in extensive beef farming systems. Ecol. Soc. 16:7.
Blanc, F., and J. Agabriel. 2008. Modelling the reproductive efficiency in a beef cow herd: Effect of calving date, bull exposure and body condition at calving on the calving-conception interval and calving distribution. J. Agri. Sci. 146:143-161.

Bourdon, R. M., and J. S. Brinks. 1987. Simulated efficiency of range beef production. III. Culling strategies and nontraditional management systems. J. Anim. Sci. 65:963-969.

Darnhofer, I., S. Bellon, B. Dedieu, and R. Milestad. 2010. Adaptiveness to enhance the sustainability of farming systems. A review. Agron. Sustain. Dev. 30:545-555.

Dedieu, B., and S. Ingrand. 2010. Incertitude et adaptation: Cadres théoriques et applications à l'analyse de la dynamique des systèmes d'élevage. INRA Prod. Anim. 23:81-89.

Doren, P. E., C. R. Shumway, M. M. Kothmann, and T. C. Cartwright. 1985. An economic evaluation of simulated biological production of beef cattle. J. Anim. Sci. 60:913-934.

Flanagan, D. 2005. Java in a nutshell. 5th ed. O'Reilly Media, Sebastopol, CA.

Gunderson, L. H. 2000. Ecological resilience-In theory and application. Annu. Rev. Ecol. Syst. 31:425-439.

Ingrand, S., H. Bardey, and J. Brossier. 2007. Flexibility of suckler cattle farms in the face of uncertainty within the beef industry:Aa proposed definition and an illustration. J. Agric. Educ. Ext. 13:39-48.

Jouven, M., J. Agabriel, and R. Baumont. 2008. A model predicting the seasonal dynamics of intake and production for suckler cows and their calves fed indoors or at pasture. Anim. Feed Sci. Technol. 143:256-279.

Lemery, B., S. Ingrand, B. Dedieu, and B. Dégrange. 2005. Agir en situation d'incertitude: Le cas des éleveurs de bovins allaitants. Econ. Rurale 285:57-69.

Liénard, G., M. Lherm, M. C. Pizaine, J. Y. Le Maréchal, B. Boussange, and J. Y. Belard. 2002. Adaptation des élevages de bovins allaitants. Références sur 10 ans (1989-1999) d'un groupe d'éleveurs du Limousin. INRA Prod. Anim. 15:273-291.

Mosnier, C., J. Agabriel, M. Lherm, and A. Reynaud. 2009. A dynamic bio-economic model to simulate optimal adjustments of suckler cow farm management to production and market shocks in France. Agric. Syst. 102:77-88.

Mosnier, C., J. Agabriel, P. Veysset, D. Bebin, and M. Lherm. 2010. Evolution et sensibilité aux aléas des résultats technicoéconomiques des exploitations de bovins allaitants selon les profils de production. INRA Prod. Anim. 23:91-102.

Nix, J. M., J. C. Spitzer, G. L. Burns, and B. B. Plyler. 1998. A retrospective analysis of factors contributing to calf mortality and dystocia in beef cattle. Theriogenology 49:1515-1523.

Nozières, M. O., C. H. Moulin, and B. Dedieu. 2011. The herd, a source of flexibility for livestock farming system faced with uncertainties? Animal 5:1442-1457.

Olesen, J. E., and M. Bindi. 2002. Consequences of climate change for European agricultural productivity, land use and policy. Eur. J. Agron. 16:239-262.

Palumbi, S. R., K. L. McLeod, and D. Grünbaum. 2008. Ecosystems in action: Lessons from marine ecology about recovery, resistance, and reversibility. BioScience 58:33-42.

Pang, H., M. Makarechian, J. A. Basarab, and R. T. Berg. 1999. Structure of a dynamic simulation model for beef cattle production systems. Can. J. Anim. Sci. 79:409-417.

Pérochon, L., S. Ingrand, C. Force, B. Dedieu, F. Blanc, and J. Agabriel. 2011. SIMBAL: A herd simulator for beef cattle. In: D. Sauvant et al., editor. Modelling nutrient digestion and utilization in farm animals. Wageningen Academic Publishers, Wageningen, the Netherlands. p. 354-363 
Reisenbauer Leesburg, V. L., M. W. Tess, and D. Griffith. 2007. Evaluation of calving seasons and marketing strategies in Northern Great Plains beef enterprise. II. Retained ownership systems. J. Anim. Sci. 85:2322-2329.

Roughsedge, T., P. R. Amer, and G. Simm. 2003. A bio-economic model for the evaluation of breeds and mating systems in beef production enterprises. Anim. Sci. 77:403-416.
Saltelli, A., K. Chan, and E. Scott. 2000. Sensitivity analysis. John Wiley, New York.

Sprent, P. 1989. Applied nonparametric statistical methods. Chapman and Hall, London.

Tess, M. W., and B. W. Kolstad. 2000. Simulation of cow-calf production systems in a range environment. I. Model development. J. Anim. Sci. 78:1159-1169. 